\title{
Histological changes and changes of phosphatase in the liver of rabbits when heated after vagotomy
}

\author{
By \\ Isamu Ono \\ Department of Anatomy, School of Medicine, Keio-Gijuku University, Tokyo
}

According to Abe and his colaborators, it was confirmed that, when rabbits were heated, the regulation of body temperature began against heating and the regulation by the chemical reaction in the liver is led through the vagus. I have already made the report on the water content of blood, body temperature and the histo-and cytological changes of the liver (Ono, '53a, b, c, '54a, b). When rabbits were heated after vagotomy, I investigated changes of their body temperature, water content of blood and liver. My work is given below:

\section{Material and method}

The apparently healthy adult rabbit fasting for 24 hours was used as the control. 13 apparently healthy adult rabbits were put in the baskets at room temperature, after the vagus of both sides were cut just below the diaphragm. 6 rabbits were kept for 3 hours in a thermostat at the temperature of $28^{\circ} \mathrm{C}$ (relative humidity $60-90 \%$ ), after 21 hours from the operation, during this intervals the room temperature was $10^{\circ}-20^{\circ} \mathrm{C}$ (relative humidity $50-70 \%$ ). The other 7 rabbits were put in baskets for 24 hours after the operation. Then, the small pieces of liver were fixed with $10 \%$ formalin and cold aceton respectively. After they were fixed, the paraffin sections were made 4-5 micron thick. For the purpose of the histological research, the sections fixed with formalin were stained with hematoxylin-eosin. For the determination of phosphatase, Gomori's revised method was used on the sections fixed with aceton. During the heating experiments, every 30 minutes, the body temperature was measured with the thermometer inserted $5 \mathrm{~cm}$ deep into the anus. At the same time blood was 
taken from the ear lobe and the amount of homoglobin was measured by Sahli's method.

\section{Observations}

The body temperature of the heated rabbit increased $0.2^{\circ}-1.0^{\circ} \mathrm{C}$. The Sahli's count shows scarcely any difference (Table I). I have reported upon the histological figure of the control rabbit in the previous paper (Ono, '53a).

Table I

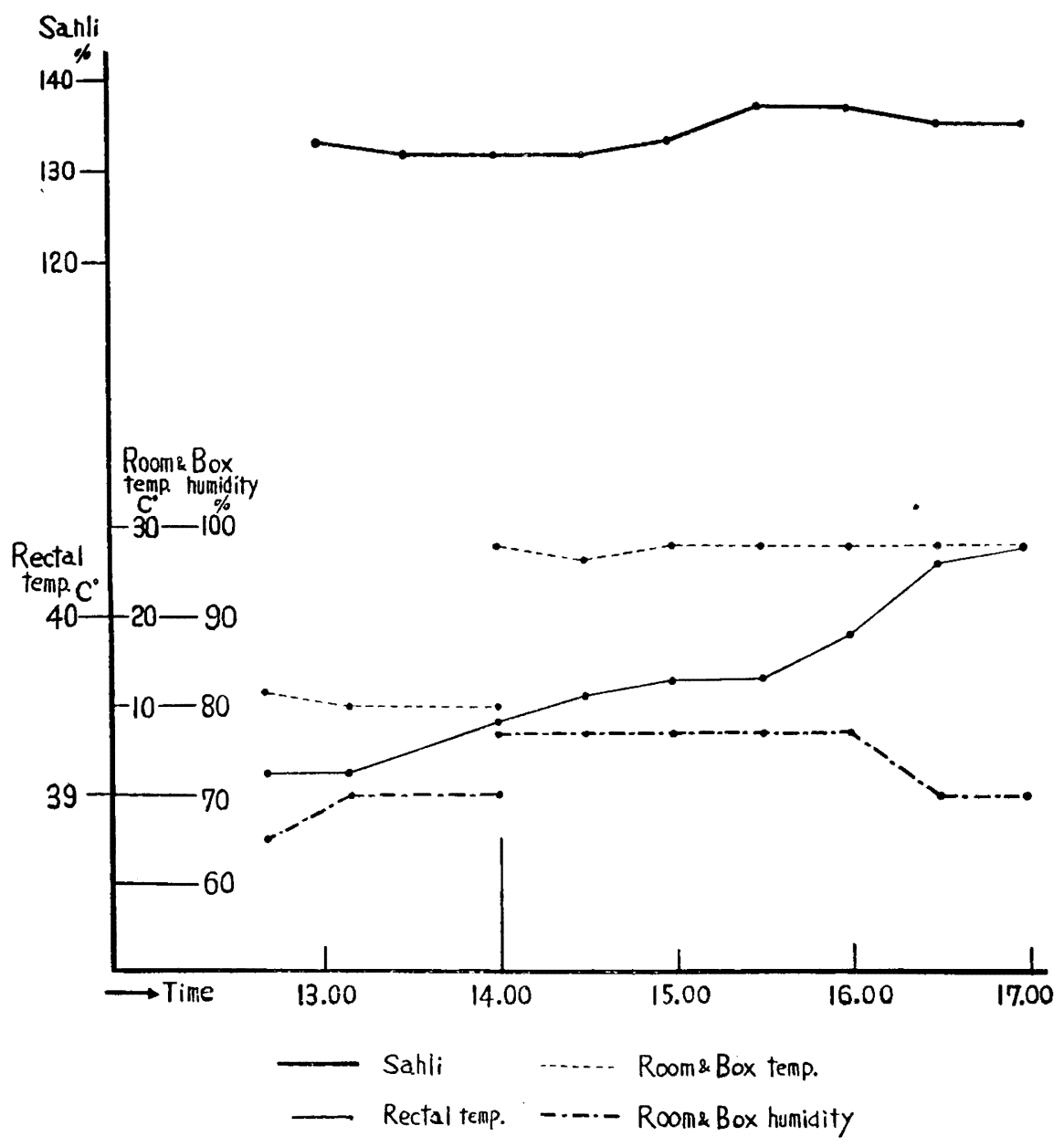

As shown in Fig. 1, at the peripheral region of the lobule of the vagotomized rabbit, the form and stainability of the hepatic cell scarcely differs from the control case. But slightly more vacuomes regarded as 
the fat droplets are noticed in the cytoplasm, comparing with the control. The hepatic cell cords show irregular arrangement and this figure is almost equal to those of the control. The infiltration of round cell is distinct around the interlobular bile duct. The central region of the lobule shows hardly any differences as compared with the control (Fig. 2). There is no difference between the number of vacuomes regarded as the fat droplets in the cytoplasm of the hepatic cell and that of the control, too. The congestion, reducing of liver cells and enlargement of hepatic sinusoid are not noticed.

As shown in Fig. 3 the hepatic cells in the peripheral region of the lobule of experimental rabbits heated after vagotomy shows the many vacuomes regarded as the fat drops in the cytoplasm, and swell to some extent. The round cell infiltration is seen around the interlobular bile duct.

At the central region of the lobule, many vacuomes slightly regarded as fat droplets are seen and there are erythrocytes in the hepatic sinusoid, but the dilatation of sinusoid is not seen. This is the figure of the slight congestion (Fig. 4).

I have already made the report upon the detail of the acid and alkaline phosphatase activity of the hepatic cell of the control rabbit (Ono, '54b).

The observation about the phosphatase activity of the liver of the vagotomized rabbit is as follows:

Concering acid phosphatase, in the cytoplasm of hepatic cell at the peripheral region of the lobule, some small granules and filamentous substances with strong activity, many slightly filamentous substances with weak activity are seen (Fig. 5). On the wall of the bile capillary and in the cytoplasm of the hepatic cell at the side of the bile capillary considerably strong activity is observed. As shown in Fig. 6 the localization of the activity in the cytoplasm of the liver cell shows hardly any difference between the central region of the lobule and the periphery, but at the center, the number of the granules and filamentous substances showing activity are less and the activity is weaker than those of the periphery. As compared with the control (Ono, '54b, Figs. 5 and 6), at the periphery and the center of the lobule too, the activity of the cytoplasm reduces strikingly, but the activity of the nucleus is almost equal.

As for alkaline phosphatase, in the cytoplasm of hepatic cell at the periphery of the lobule I observed many filamentous substances with strong activity near the bile capillary and few filamentous substances 
with strong activity. A few filamentous substances with weak activity are seen in the other parts. The wall of bile capillary and the contents of it demonstrate the strong activity (Fig. 7). As shown in Fig. 8, at the center of the lobule, the localization of activity is almost equal to that of the periphery, but the activity is slightly weaker. The commashaped and granular substances with strong activity in the cytoplasm of the control (Ono, '54b. Figs. 5 and 6) are hardly seen and the hepatic cell reduces in the center and periphery of the lobule. The activity of acid phosphatase in the liver of rabbit heated after vagotomy is as follows :

Concerning acid phosphatase, as shown in Fig. 9, in the cytoplasm of the hepatic cell at the periphery of the lobule there are some parts regarded as the fat droplets without activity, in the other part almost the same activity is shown in the cytoplasm of the hepatic cell of the periphery of the lobule, as noticed in the vagotomized rabbit, but it is noticed that the granular and filamentous substances are slightly enlarged and increase their number. The wall of bile capillary and its contents have stronger activity than that of the vagotomized rabbit. As shown in Fig. 10, localization of the activity is almost equal to that of the peripheral region, but the activity of the former is slightly stronger than that of the latter.

Concerning alkaline phosphatase, as shown in Fig. 11, there is the part regarded as fat droplets without any activity in the cytoplasm of the hepatic cell at the peripheral region of the lobule and in the other parts, it is noticed that the granules and the filamentous substances are thicker, longer and relatively more numerous than that of the cytoplasm of the hepatic cell at the periphery of the lobule of the vagotomized rabbits, also there are many filamentous substances with weak activity. The filamentous substances with strong activity increase at the side of bile capillary of the cytoplasm and the activity of the bile capillary and its contents increase, too.

As shown in Fig. 12, at the central region of the lobule, the changes are almost equal to those of the periphery, but the activity of the center is generaly stronger than that of the periphery.

\section{Discussion}

I have already reported that, when the normal rabbits were heated at $28^{\circ} \mathrm{C}$, the body temperature of them did not increase and often decreased and the water content of blood increased on that occasion 
(Ono, '53a). When a rabbit is heated in the thermostat at the temperature of $28^{\circ} \mathrm{C}$ after vagotomy, the rise of body temperature is recognised and no remarkable change of the Sahli's count of blood can be seen, namely there are not any significant changes of the water content of blood. That confirms the fact that the mechanism of the parasympathetic body temperature regulation in a narrow sense and of the parasympathetic blood osmotic pressure regulation take place chiefly in the liver through the vagus.

Koga (1937) has made the report upon the experiment on excision of the right vagus of rabbit at the lower end of the esophagus. He has reported as follows. After 3-31 days from the operation, he investigated the liver and noticed congestion and remarkable fatty degeneration. There were relatively a few numbers of the fat droplets in the hepatic cells at the central region of the lobule and many fat droplets at the periphery, which were varied in size and were irregularly distributed in the cytoplasm. About the nucleus, he noticed a pyknosis shaping crescent and that some nucleus vanished. He saw the infiltration of round cells and big spindle-shaped cells in the interlobular connective tissue and that these cells stored fat.

His view is almost equal to my work of the histological figure of the liver of vagotomized rabbit. But according to my work, I don't notice the fatty degeneration and especially pyknosis, congestion and infiltration of big spindle-shaped cell. The difference between my work and his report, I guess, comes from the fact that my work was carried out after 24 hours from the operation and this period is shorter than that of his report.

I have already reported that congestion, reducing of hepatic cell and dilatation of hepatic sinusoid are noticed in the histological figure of the liver of the rabbit heated at $26^{\circ}-28^{\circ} \mathrm{C}\left(\mathrm{Ono},{ }^{\prime} 53 \mathrm{a}\right)$. Comparing the histological figure of the rabbit heated after vagotomy with that of the vagotomized rabbit, the former shows more vacuomes regarded as the fat droplets than the latter and slight congestion is noticed but reducing of hepatic cell, dilatation of hepatic sinusoid and remarkable congestion are not shown. Though I have pointed out that reducing of hepatic cell and dilatation of hepatic sinusoid was closely related with the water content of blood, this intimate correlation is conceivable from the above point of view, too.

It can be considered that both the vagotomized rabbit and the rabbit heated after vagotomy show almost the same changes of acid phosphatase, as in the case of alkaline phosphatase. When phosphatase 
of the liver of the vagotomized rabbit is compared with that of the control, the former shows a remarkable reduction of activity. In this point, it is recognised that there is abnormality of metabolism in the liver on account of vagotomy. As compared rabbits heated after vagotomy with the vagotomized rabbits, the former show somewhat more increase of activity than the latter and the central region of the lobule shows stronger activity than the periphery does. I think it is for this reason that there are many vacuomes regarded as the fat droplets in the hepatic cells at the peripheral region. Is the fact, that the liver shows morc or less reaction against heating still after cuting vagus, due to the direct stimulus to the liver by the increase of blood temperature? Is the fact due to the stimulus through the nerve fibre of the spinal parasympathetic nervous system of Kure ('40)? Is the fact due to the stimulus through the sympathetic fibre? I can not solve these questions. But the reaction of liver against heating, when the vagus is cut, plainly differs from that of the liver of the heated rabbit without vagotomy. I can not say that the reaction disappears, but I think I may say the reaction makes it's appearance in such a degree that it is barely noticed.

\section{Conclusion}

7 rabbits were vagotomized and after 24 hours from the operation, the small pieces of their livers were fixed. 6 vagotomized rabbits were heated for 3 hours at $28^{\circ} \mathrm{C}$, and body temperature and the water content of blood were measured. Body temperature rose $0.2^{\circ}-1.0^{\circ} \mathrm{C}$ and the water content of blood did not show any apparent changes. Just after heating small pieces of the liver were fixed and the histological figure and phosphatase of the liver were investigated.

1. The vagotomized case.

a. The histological figure. More vacuomes regarded as fat droplets are noticed in the cytoplasm. Round cell infiltration is noticed in the interstitial connective tissue.

b. Acid phosphatase. Activity apparently becomes weak in comparison with the control. Very weak activity is noticed in the cytoplasm of hepatic cells and slightly strong activity on the wall of bile capillary. Activity in the central region of the lobule is weaker than that in the periphery.

2. The experimental case heated after vagotomy.

a. The histological figure. Except for the existence of vacuomes 
Histological changes and changes of phosphatase in the liver of rabbits etc.

regarded as the fat droplets in the cytoplasm and slight congestion in comparison with the vagotomized rabbit, there is hardly any difference.

b. Acid phosphatase. It is noticed that activity of the cytoplasm of the hepatic cell, on the wall of bile capillary and of its content increases as compared with the vagotomized case. Activity in the central region of the lobule is stronger than that in the periphery.

c. Alkaline phosphatase. Activity of the cytoplasm of the hepatic cell, on the wall of bile capillary and of its contents shows the increase as compared with that of the vagotomized case. Besides, activity in the central region of the lobule is stronger than that in the periphery.

\section{References}

Koga, H. 1937 Vorderhirn und autonomes Nervensystem mit Berücksichtigung der inneren Organe. III. Teil. Experimentelle Untersuchung über den Einfluss der peripheren autonomen Nerven auf Blutstauung und Fettansatz der Leber. Fukuoka Acta Medica 30: 2021-2041.

Kure, K. 1940 Autonomic nervous system. Kokuseido, Tokyo (Japanese)

Ono, I. 1953a Studies on histological, cytological and cytochemical changes in the liver of rabbits caused by the alteration of atmospheric temperature. I. Histological changes at $26^{\circ}-28^{\circ} \mathrm{C}$. Fol. anat. jap. $25: 149-154$

$1953 \mathrm{~b}-\mathrm{II}$. The changes of polysaccharide at $26^{\circ}-28^{\circ} \mathrm{C}$. Fol. anat. jap. 25 : 155-158

$.1953 \mathrm{c}$ III. Changes of mitochondria at $26^{\circ}-28^{\circ} \mathrm{C}$. Fol. anat. jap. 25 :

159-161

- 1954a IV. Histological and cytological studies and changes of polysaccharide at $35^{\circ}-37^{\circ} \mathrm{C}$. Fol. anat. jap. 26 : 167-172

1954b Histochemical changes of alkaline and acid phosphatase in the liver cells of rabbits after heating. Fol. anat. jap. 26: 173-177

\section{Explanation of figures}

Figs. 1-4. 10\% formalin fixation, stained with hematoxylin-eosin.

Fig. 1. vagotomized rabbit, periphery of the hepatic lobule.

Fig. 2. vagotomized rabbit, central region of the hepatic lobule.

Fig. 3. heated rabbit after vagotomy, periphery of the hepatic lobule.

Fig. 4. heated rabbit after vagotomy, central region of the hepatic lobule.

Figs 5-12. fixed with cold aceton, phosphatases were demonstrated by Gomori revised method.

Figs. 5-8. vagotomized rabbit.

Fig. 5. periphery of the hepatic lobule, acid phosphatase.

Fig. 6. central region of the hepatic lobule, acid phosphatase.

Fig. 7. periphery of the hepatic lobule alkaline phosphatase.

Fig. 8. central region of the hepatic lobule, alkaline phosphatase.

Figs. 9-12. heated rabbit after vagotamy. 
Fig. 9. periphery of the hepatic lobule, acid phosphatase.

Fig. 10. central region of the hepatic lobule, acid phosphatase.

Fig. 11. periphery of the hepatic lobule, alkaline phosphatase.

Fig. 12. central region of the hepatic lobule, alkaline phosphatase. 
Plate I
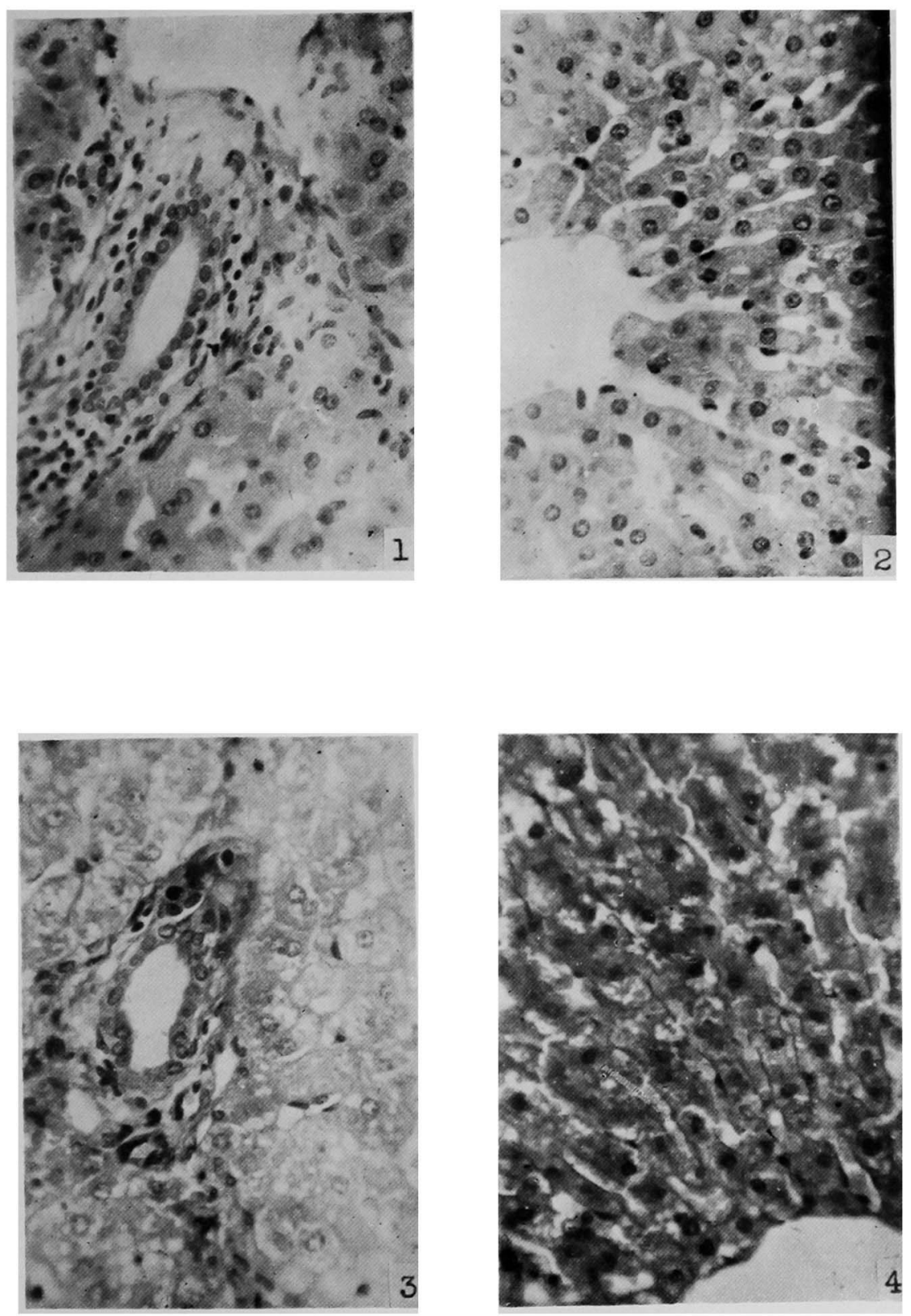

I. Ono 
Plate II
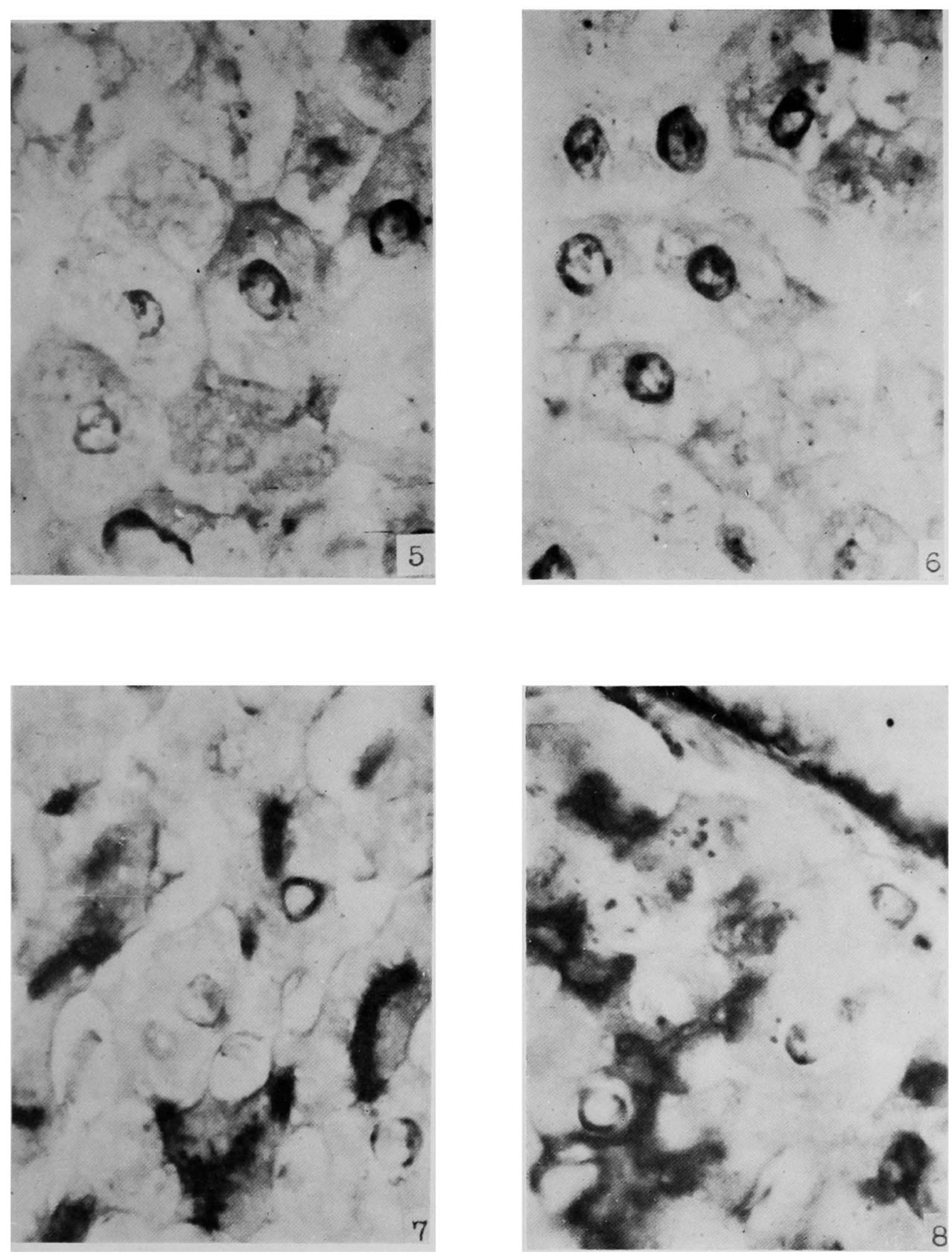
Plate III
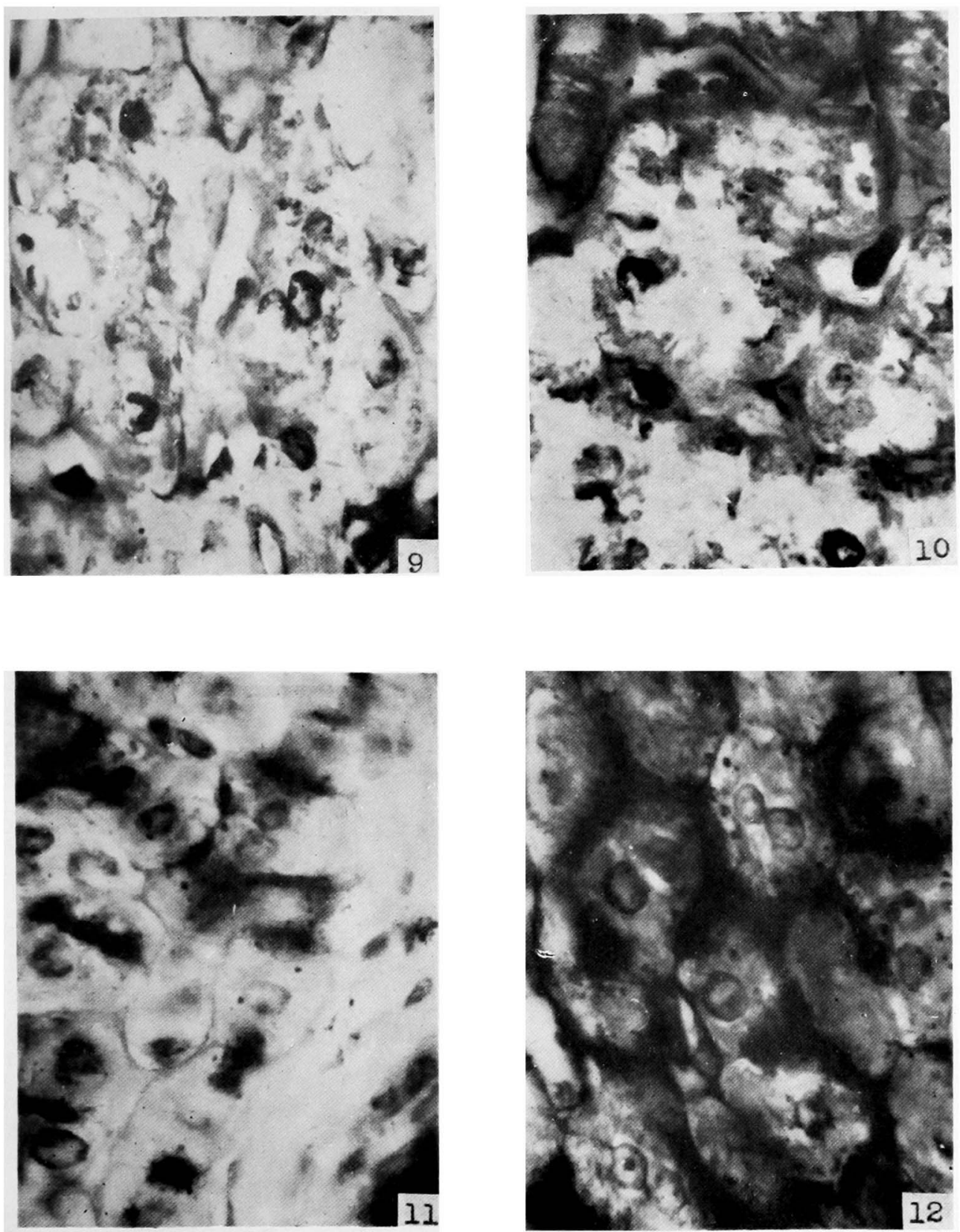